\title{
The collaboration model delivering land use information for Australia
}

\author{
J.B. Stewart and J.L. Mewett \\ Australian Bureau of Agricultural and Resource Economics and Sciences, Department of Agriculture, GPO \\ Box 858, Canberra City, ACT 2601 \\ Email:jane.stewart@agriculture.gov.au
}

\begin{abstract}
To collaborate is to work together towards a common goal. A collaboration model is the framework that facilitates this cooperation. The Australian Collaborative Land Use and Management Program (ACLUMP), overseen by the National Committee for Land Use and Management Information (NCLUMI), was established in 2000 and is recognised as an exemplar in cross-jurisdictional natural resource coordination. ACLUMP is a partnership between state, territory and federal government land management agencies, providing consistent land use information across the whole continent. ACLUMP's collaboration model:

1. Recognises the different roles and responsibilities of state and federal agencies within a national context.

2. Identifies common strategies and priorities to facilitate joint investment.

3. Encourages a culture of regular meetings to discuss land use policy and planning issues and to share technical expertise.

4. Responds to emerging issues and technological advances.

Collectively, ACLUMP has developed a national approach to the mapping and classification of Australia's land use. Technical standards are applied by all parties in the production of 'national' and 'catchment'-scale land use spatial information products accessible through jurisdictional data portals or the ACLUMP website. In an environment of short-term funding and regular organisational restructuring, ACLUMP has persisted. ACLUMP's experiences could be beneficial to other multi-organisational and inter-jurisdictional groups wishing to establish a successful collaboration model.
\end{abstract}

Keywords: Land use, spatial data, national standards, Australian Collaborative Land Use and Management Program 


\section{INTRODUCTION}

The Australian Collaborative Land Use and Management Program (ACLUMP) is recognised as an exemplar in cross-jurisdictional natural resource coordination (Thackway 2018a). ACLUMP is a partnership between state, territory and federal government land management agencies, providing consistent land use information across the whole continent (ACLUMP 2016). Partners work together to establish national guidelines for consistent land use mapping coverage for Australia at 'national' and 'catchment' scales. ACLUMP is coordinated by the Australian Bureau of Agricultural and Resource Economics and Sciences (ABARES) within the Australian Government Department of Agriculture and overseen by the National Committee for Land Use and Management Information (NCLUMI).

Lesslie et al. (2006), Barson et al. (2008) and Hicks (2018) provide a history of the development of ACLUMP. ACLUMP was established in 2000 in response to increasingly complicated and complex land use policy and planning issues facing all Australian land management jurisdictions, including food security, vegetation and carbon management, biosecurity, climate change, sustainable agriculture and water management. At the same time, Australia started systematic reporting in respect to forest cover and national greenhouse gas emissions, as a result of the Kyoto Protocol and United Nations reporting requirements. Each of these issues called for a coordinated and cooperative approach to developing a responsive national land use infrastructure. Key elements of the infrastructure included mapping, coordination and standards, communication and dissemination, and analysis and reporting.

\section{BACKGROUND}

Before 1999, the availability of detailed mapping of land use at national and regional scales in Australia was limited and uncoordinated. Australian, state and territory government agencies independently produced land use mapping at a range of scales using a variety of cartographic methods and classification systems.

ACLUMP mapping products are in strong demand for a range of land management purposes and there is widespread adoption of agreed standards. Land use information is critical for planning, policies and decisionmaking. It is required by all levels of government, regional natural resource management groups, industry groups, community groups, the research community and land managers. The importance of ACLUMP and the information it provides is widely recognised.

This paper is primarily focused on the land use information and mapping aspects for which there is a longer history, though the collaboration model similarly applies to work on the other landscape attributes of land cover and land management under the auspices of NCLUMI and ACLUMP.

\section{THE ACLUMP COLLABORATION MODEL}

\subsection{Roles and responsibilities}

Under the Australian Constitution, each state and territory has responsibility for land use policy, planning and management. Each state has varying legislative drivers and land use pressures. Through ACLUMP a comprehensive and consistent land use framework has been developed for land use classification and mapping, which is applied by the states (Figure 1). Catchment-scale land use data are validated, provided to ABARES for quality assurance and, since 2008 , released annually as an updated national compilation. ACLUMP partners have agreed on land use mapping goals for comprehensiveness, accuracy, currency and scale (ABARES 2015).

ACLUMP has created its governance structure to be resilient. Leadership within NCLUMI is a shared responsibility, anticipating, adapting and responding to changing needs and shifting priorities. Decisions, strategic and technical, are agreed, built on trust between the partners.

Since 2009, ACLUMP has operated under five-yearly Memoranda of Understanding. In signing, partners agree to the achievement of ACLUMP's objectives and the roles and responsibilities of ACLUMP and NCLUMI. NCLUMI and ACLUMP lost formal reporting arrangements when the Standing Council on Primary Industries was disbanded by the Council of Australian Governments (COAG) in 2013, and having a Memorandum of Understanding has ensured continuity of the program. NCLUMI (like the similar National Committee on Soil and Terrain) is also listed under the Department of Agriculture on the Government Organisation Register. 


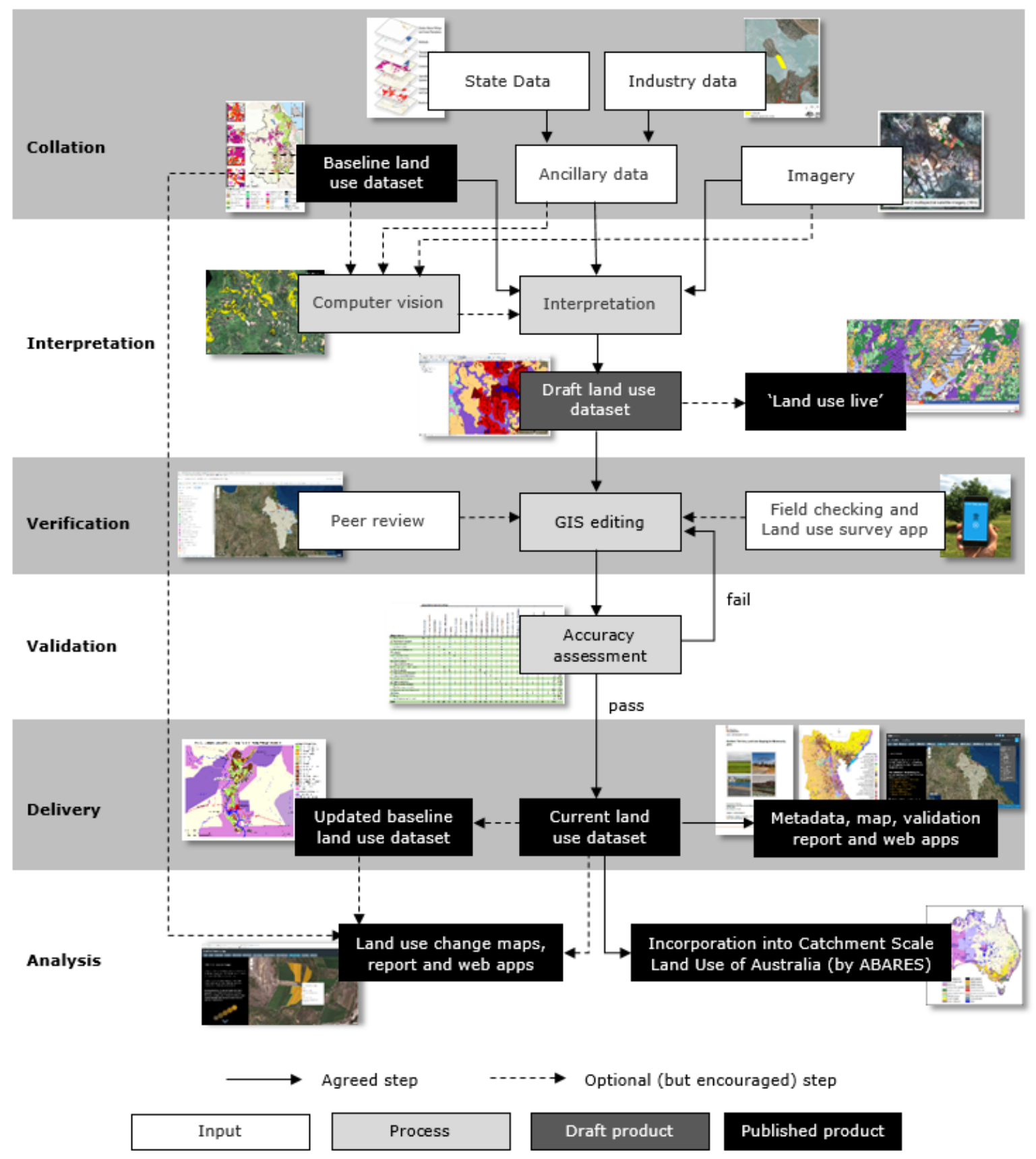

Figure 1. ACLUMP nationally agreed catchment-scale land use mapping procedure (ABARES in prep.).

\subsection{Investment strategies and priorities}

ACLUMP started with strong investment in the early 2000s from the Natural Heritage Trust (NHT), National Action Plan for Salinity and Water Quality (NAP), National Land and Water Resources Audit, Murray Darling Basin Commission, Australian Greenhouse Office and state and territory agency partners for nationally consistent land use and land management practices information. Agreed was that these data and integrated analyses were critical to:

- Monitor and report natural resource condition and trend for national processes such as NHT/NAP and State of the Environment.

- Target and guide investment in high priority natural resource management issues.

- Provide performance information for agricultural industries and Environmental Management Systems. 
- Model landscape processes that affect the natural resource base and generate problems such as salinity and water quality.

Later investment has come from Caring for our Country and the National Landcare Program (NLP) with coinvestment from state and territory agency partners. These investments have had similar focus on natural resource management, but also a new user group for biosecurity purposes such as emergency disease management and planning of surveillance activities. The last investment under NLP saw the largest annual update to the Catchment scale land use of Australia dataset in 2017 with new mapping for 585 million hectares or 76 per cent of Australia.

Collectively being engaged, anticipating and nimble to funding opportunities has served ACLUMP well. A clear and shared vision has also focused which opportunities to pursue.

\subsection{Relationship building}

\section{Annual face-to-face meeting}

ACLUMP and NCLUMI hold adjoining face-to-face meetings each year. The ACLUMP technical workshops are structured around a theme reflecting the program's current focus. These meetings are rotated through the jurisdictions, allowing the host jurisdiction the opportunity to highlight their activities to ACLUMP but also to influential local groups. It also reinforces to each host organisation that they are part of a wider community of practice. Another important component is the field trip which assists with prioritising issues that ACLUMP should consider in its forward workplan (such as ACLUMP 2010). Modest funding is provided to the host to cover the costs of these annual meetings.

When required, additional workshops are held to progress particular topics or funded activities, for example 'land use mapping by exception', and ground cover monitoring. Working groups are formed to progress technical issues, such as classification of land cover and land use, and field measurement of ground cover, to inform ACLUMP technical standards.

\section{Rotating chair}

The chair of NCLUMI rotates through the jurisdictions every 2 to 3 years. This promotes ownership amongst the jurisdictions and allows jurisdictions to ensure that the work of ACLUMP aligns with their own goals and policy drivers. It has also led to former chairs being champions for ACLUMP, even when they are no longer participants.

\section{Constant secretariat}

The Department of Agriculture is the 'sponsor' of national coordination of land use information and provides secretariat support for NCLUMI and the development of ACLUMP through its research bureau, ABARES. The stability of this function within ABARES has enabled the group to maintain momentum and the group's corporate knowledge. In this role, ABARES also maintains the group's external website providing access to ACLUMP's datasets, technical standards and publications; prepares the annual national spatial compilation of catchment-scale land use; and often has secured funding to support the group's activities.

\section{Collegiate}

ACLUMP has a collegiate atmosphere with partners genuinely sharing their expertise, tools and data to collectively improve products and models. This prevents duplication of effort and enables advances by one jurisdiction to be trialled in others for adoption nationally. An example is the development of an improved validation technique for the catchment-scale land use datasets (Denham 2005) which is now part of the national standards (ABARES 2011). This is greatly facilitated by the annual face-to-face meeting and regular teleconferences, and stability in membership with a good mix of old and new members. ACLUMP also engages and cooperates with research and development corporations, government biosecurity agencies, industry groups and other government initiatives to obtain and share data and expertise. A current example is the National Strategy for Environmental-Economic Accounting agreed to by all environment ministers, which is to deliver a national land account.

\subsection{Remaining valued}

The initial focus of ACLUMP was land use information for natural resource management. In recent years, the group has responded to biosecurity requirements and currently to requirements for national land accounts. These additional areas of focus can be accommodated with the flexible land use classification (releasing version 8; ABARES 2016), new mapping methods (such as computer vision) for biosecurity and early 
engagement to manage expectations on the level of spatial and temporal detail expected for consistent national reporting of land use change. Reviewing and updating technical standards and how ACLUMP data products are validated (such as developing a field app), delivered (such as 'Land use live' to provide the most current data as it is available) and viewed (such as web apps), are also part of retaining the value users place in ACLUMP data products (Figure 1).

Various agricultural industries are now involved in providing and/or validating data. For example, in Tasmania, the dairy and wine industry work with the Tasmanian ACLUMP partners to improve mapping of their industries for faster and accurate responses during biosecurity incidents and natural disasters. Recent field validation to commodity level in the Northern Territory was led by the NT Farmers with the NT ACLUMP partners. ACLUMP has also been responsive to industry, such as updating its classification to better capture production nurseries (ABARES 2016). Queensland partners have also developed online peer review maps to allow industry (such as horticultural tree crop growers) and local experts to easily visualise the land use data and provide real-time validation (for example QLUMP 2019).

Product views, downloads and applications are monitored and evaluated to support ACLUMP's business case. Continuous improvement in products in response to user needs, and for efficiency, are facilitated through the partner collaboration.

\section{ACLUMP ACHIEVEMENTS}

Twenty years ago, Australia did not have a nationally consistent, spatially explicit and quantitative picture of how it used its land. Through ACLUMP, national standards have been developed and refined to map and classify Australia's land uses. This has resulted in:

- The release of the first national-scale Land use of Australia dataset in 2001, with datasets available for 1992-93, 1993-94, 1996-97, 1998-99, 2000-01, 2005-06 and 2010-11, with 2015-16 under construction.

- Completed continental coverage of catchment-scale land use mapping in 2008, with annual updates of the Catchment scale land use of Australia dataset since. The largest update was in 2017 and was accompanied by the first release of a commodity-level dataset. The 2018 update (ABARES 2019) can be viewed on NationalMap and as land use profiles.

- Four editions of the Guidelines for land use mapping in Australia: principles, procedures and definitions (the latest ABARES 2011) plus an Addendum (ABARES 2015) with the fifth edition in preparation.

- $\quad$ Eight versions of the Australian Land Use and Management Classification (the latest ABARES 2016). The classification has evolved to accommodate new land uses and commodity-level mapping.

- Recognition of ACLUMP data products as Australian Foundation Spatial Data by ANZLIC - the Spatial Information Council.

ACLUMP land use datasets have been used in national and regional assessments including: assessing Rural Land Partnership tenders under the National Landcare Program; Bioregional Assessments to understand potential impacts of coal seam gas and large coal mining developments on water resources and water-dependent assets; assessing Emission Reduction Fund applications; horticulture tree crops in Queensland impacted by Tropical Cyclone Debbie; estimating the economic impact of Pierce's disease on the Australian grape industry; and as a key input to water quality modelling for the Paddock to Reef Integrated Monitoring, Modelling and Reporting Program for the management and protection of the Great Barrier Reef. ACLUMP land data informs or are embedded in various jurisdictional applications such as the NSW Native Vegetation Regulatory Map and the Queensland Web-based Agricultural Land Information (WALI).

\section{RECOMMENDATIONS FOR MULTI-ORGANISATIONAL INTER-JURISDICTIONAL COLLABORATION}

ACLUMP focuses on communication and coordination, data provision and impact. At its core, ACLUMP collaborates to deliver and continually improve datasets relevant to its partners and its diverse users. Thackway (2018b) provides 17 characteristics of regional-scale national datasets used by policy and planning for more than 10 years (termed 'enduring datasets') that are applicable to ACLUMP's data products. These characteristics, with the learnings from the ACLUMP collaboration model presented in this paper, provide recommendations for successful multi-organisational inter-jurisdictional collaboration. 


\subsection{Recommendation 1: Set roles and responsibilities}

Define and articulate the problem, issue or key questions that the group/data/model is to address. This should have strong relevance to one or more policies and programs. Use this to develop an agreed conceptual model, framework or information hierarchy. Establish unambiguous governance arrangements with an effective champion, sponsor or leader.

\subsection{Recommendation 2: Determine investment strategies and priorities}

To be enduring requires recurrent adequate resourcing, both people and dollars. Products should be underpinned by sound technical, scientific and information technology (IT) support and data management enabling interoperability and a capacity to integrate. Know who your key stakeholders and users are and regularly revisit your priorities and business case. Be prepared to seek new partnerships and funding providers. Be flexible in your approach to ongoing group/data/model development.

\subsection{Recommendation 3: Cultivate relationships and cohesion}

Members should see value in their involvement and the outputs produced, and the benefits that a collective 'branding' provides. Regularly communicate group goals and expectations of members. Provide the required tools for collaboration, accommodating for different levels of technology access. Leverage members' strengths and recognise members' contributions and achievements. Show respect for other members and differing points of view. Be welcoming to new members. Allow members to nominate and vote for their chair/leader.

\subsection{Recommendation 4: Remain relevant and valued}

Data/models should be peer reviewed and published. Products should be discoverable, reusable and accessible, and relevant to a range of users (i.e. partners, clients, planners, on-ground managers, research and education). Members should be committed to continuous improvement in the data/model (both spatial and temporal). Collaboration should encourage innovation through the sharing of experiences, data, tools and expertise. Stakeholders and users should be active participants in the scoping, development and delivery of the data/model and its outputs with their feedback and input welcomed, because the likelihood of use, endorsement and promotion of the products is enhanced by their involvement. Monitor and evaluate the impact of the group's data products/models through web analytics, citations, policy and program applications, and engagement with stakeholders and users. Use this impact assessment to inform the business case and potential new partners and/or investors.

\section{ACKNOWLEDGMENTS}

Current partners of the Australian Collaborative Land Use and Management Program (ACLUMP) are: NSW Department of Planning, Industry and Environment; NT Department of Environment and Natural Resources; Queensland Department of Environment and Science; SA Department for Environment and Water; Tasmanian Department of Primary Industries, Parks, Water and Environment; Victorian Department of Jobs, Precincts and Regions; WA Department of Primary Industries and Regional Development; Australian Government Department of Agriculture; Australian Bureau of Statistics; Bureau of Meteorology; Australian Government Department of the Environment and Energy; Geoscience Australia; Murray Darling Basin Authority; Commonwealth Scientific and Industrial Research Organisation (CSIRO); Terrestrial Ecosystems Research Network (TERN). In addition to these partners, the National Committee on Soil and Terrain and the ACT Government Environment, Planning and Sustainable Development Directorate serve as observers on the National Committee for Land Use and Management Information (NCLUMI). ACLUMP's products can be accessed via its website www.agriculture.gov.au/landuse.

\section{REFERENCES}

ABARES (2011). Guidelines for land use mapping in Australia: principles, procedures and definitions, 4th edition, A technical handbook supporting the Australian Collaborative Land Use and Management Program, Australian Bureau of Agricultural and Resource Economics and Sciences, Canberra.

ABARES (2015). Addendum to the Guidelines for land use mapping in Australia: principles, procedures and definitions, 4th edition, Prepared by the Australian Collaborative Land Use and Management Program partners, Australian Bureau of Agricultural and Resource Economics and Sciences, Canberra.

ABARES (2016). The Australian Land Use and Management Classification Version 8, Prepared by the Australian Collaborative Land Use and Management Program partners, Australian Bureau of Agricultural and Resource Economics and Sciences, Canberra. 
ABARES (2019), Catchment scale land use of Australia-update December 2018, ABARES, Canberra, March CC BY 4.0.

ABARES (in prep.). Guidelines for land use mapping in Australia: principles, procedures and definitions, 5th edition, A technical handbook supporting the Australian Collaborative Land Use and Management Program, Australian Bureau of Agricultural and Resource Economics and Sciences, Canberra.

ACLUMP (Australian Collaborative Land Use and Management Program) (2016). Land use information for Australia (brochure), Department of Agriculture and Water Resources, Canberra.

ACLUMP (Australian Collaborative Land Use and Management Program) (2010). Land use and land management information for Australia: Workplan of the Australian Collaborative Land Use and Management Program, Australian Bureau of Agricultural and Resource Economics and Sciences, Canberra.

Barson, M., Lesslie, R., Smith, J. and Stewart, J. (2008). Developing land cover and land use data sets for the Australian continent - a collaborative approach. In: Campbell, J.C., Jones, K.B., Smith, J.H. and Koeppe, M.T. (eds.) North America Land Cover Summit, pp. 45-73. Association of American Geographers, Washington, DC.

Denham, R. (2005). Accuracy assessment for land use mapping, Queensland Department of Natural Resources and Mines, Brisbane and the Bureau of Rural Sciences, Canberra.

Hicks, R.W. (2018). Responding to land use pressures: A state and territory perspective. In: Thackway, R. (ed.) Land use in Australia: Past, present and future, pp.85-105. ANU Press, Canberra.

Lesslie, R., Barson, M. and Smith, J. (2006). Land use information for integrated natural resources management-a coordinated national mapping program for Australia, Journal of Land Use Science, 1(1), 45-62.

QLUMP (2019). Land use summary app - Burnett Mary NRM Region, Queensland Land Use Mapping Program, Remote Sensing Centre, Department of Environment and Science, Queensland Government.

Thackway, R. (2018a). A Retrospective: The influence of Rob Lesslie-Landscape scientist, geographer and natural resources land use planner. In: Thackway, R. (ed) Land use in Australia: Past, present and future, pp.17-29. ANU Press, Canberra.

Thackway, R. (2018). National coordination of data and information to inform land use policies and programs: The recent past, the present and ideas for the future. In: Thackway, R. (ed.) Land use in Australia: Past, present and future, pp.129-143. ANU Press, Canberra. 